\title{
Affinity Tag for Protein Purification and Detection Based on the Disulfide-Linked Complex of InaD and NorpA
}

BioTechniques 33:578-590 (September 2002)

\author{
Michelle E. Kimple and \\ John Sondek \\ The University of North \\ Carolina at Chapel Hill, \\ Chapel Hill, NC, USA
}

\section{ABSTRACT}

Affinity tags are not only used for the expression and purification of recombinant proteins but also for the detection of proteinprotein interactions. Common problems with many affinity tags are excessive length, which may interfere with the structure and function of tagged proteins, and low affinity and/or specificity for primary detection and purification agents. Preliminary results suggest that the C-terminal five residues of the Drosophila protein NorpA, based on the short, covalent interaction they make with the N-terminal PDZ domain (PDZ1) of InaD, are useful as a general affinity tag. First, a PDZ1-alkaline phosphatase fusion protein specifically detects both its physiological ligand and a heterologous protein expressing the NorpA C-terminal five residues. The interaction of $P D Z 1$ with a NorpA-tagged protein is reversible by a reducing agent, which allows nitrocellulose membranes to be stripped completely and reused. In addition, a NorpA-tagged protein can specifically bind to immobilized PDZ1 resin, while other cellular proteins are washed through. After washing, the NorpAtagged protein is eluted by a reducing buffer. The NorpA tag's short length makes it the smallest affinity tag available, and its specific and high-affinity interaction with PDZ1 could yield a powerful system that improves on currently available technology.

\section{INTRODUCTION}

Inactivation no after-potential D (InaD) is absolutely required in the Drosophila phototransduction pathway, a well-characterized, $G$ protein-coupled, phospholipase C-mediated signaling cascade $(14,15,21)$. InaD is composed of five PDZ domains $(17,19,20)$, which were named for the first three proteins in which this protein-binding domain was characterized: "p" for post-synaptic density 95, "d" for discslarge, and " $\mathrm{z}$ " for zonular occludens 1 $(5,9,12)$. PDZ domains generally interact with the C-terminal 3-5 amino acids of their protein targets, including the free carboxylate group (7). The two main classes of PDZ domains, type I and type II, are divided based on the amino-acid sequences of their ligands. Type II PDZ domains bind the sequence $\Phi-\mathrm{X}-\Phi-\mathrm{COO}^{-}$, where " $\Phi$ " is a hydrophobic residue (4).

The type II N-terminal PDZ domain (PDZ1) of InaD binds the C-terminus of no receptor potential A (NorpA), the relevant phospholipase $\mathrm{C}-\beta$ isozyme in the phototransduction pathway $(1,3,17$, 19-21). The crystal structure of PDZ1 in complex with a peptide corresponding to the NorpA C-terminus shows that only the last five residues of NorpA contact PDZ1 and that a disulfide bond is the major intermolecular interaction (10). The short PDZ1 binding motif of NorpA, coupled with its covalent yet dissociable interaction, led to the hypothesis that the NorpA C-terminal residues (Thr-Glu-Phe-Cys-Ala) could be used as an affinity tag for protein detection and purification by appropriately modified PDZ1. The experiments described here aim to demonstrate that PDZ1 specifically detects not only its physiological ligand but also a heterologous protein expressing the NorpA Cterminal five residues (Figure 1A). The ability of immobilized PDZ1 to specifically purify a NorpA-tagged protein from cell lysate is also examined (Figure 1B). Because of its short, linear recognition sequence and its specific interaction with PDZ1 that is both covalent and dissociable, the NorpA tag could be an improvement on most currently available affinity tags.

\section{MATERIALS AND METHODS}

\section{Cloning and Protein Expression}

PDZ1 (residues 11-107 of InaD) and $\mathrm{CT}_{\mathrm{Dm}}$ (residues 863-1095 of NorpA) were cloned into pProEX ${ }^{\mathrm{TM}}$ HTa (Invitrogen, Carlsbad, CA, USA) and expressed in BL21(DE3) E. coli as previously described (10).

Gail was cloned into pProEX HTb (Invitrogen) and expressed in BL21 (DE3) E. coli as previously described (11). To express Goil with the NorpA tail, the Goi1 stop codon was removed using the QuikChange ${ }^{\mathrm{TM}}$ Site-Directed Mutagenesis kit (Stratagene, La Jolla, CA, USA), yielding pPro/Goi1-Stopless. Oligonucleotides that encoded for the C-terminal five amino acids of NorpA flanked by NotI half-sites (underlined) and $\mathrm{XbaI}$ half-sites (bolded) were annealed by denaturation at $94^{\circ} \mathrm{C}$ for 5 min, followed by cooling to room temperature for $15 \mathrm{~min}$ [5'-GGCCGCACGGAATTTTGTGCCTAAT-3' (sense) and 5'-CTAGATTAGGCACAAAATT- 
CCGTGC-3' (antisense)]. Annealed oligonucleotides were ligated into $\mathrm{pPro} /$ Goi1-Stopless cut with NotI and XbaI. Goi1-NorpA was expressed as described for Goil.

To create the PDZ1-alkaline phosphatase expression vector, cDNA corresponding to residues $13-107$ of InaD was amplified from a plasmid template generously provided by Dr. Bih-hwa Sheih (Vanderbilt University, Nashville, TN, USA) using PDZ1-specific primers. A $K p n I$ restriction site (underlined) was inserted into the sense primer, and a $B g l I I$ restriction site (bolded) was inserted into the antisense primer. The sequences of the PDZ1 primers used were 5'-TGGTACCGAGCTCATTCACATGGTGACCCT-3' (sense) and 5'-CAGATCTTCTTGTCGAAGGTCTGAATCTC-3' (antisense). The PDZ1 cDNA was ligated into the $\mathrm{pCR}^{\circledR}{ }^{\circledR} 2.1-\mathrm{TOPO}^{\circledR}$ vector and transformed into TOP10 chemically competent cells using the TOPO TA Cloning ${ }^{\circledR}$ System (Invitrogen). The pCR2.1/PDZ1 was purified from an overnight culture of a positive transfor-

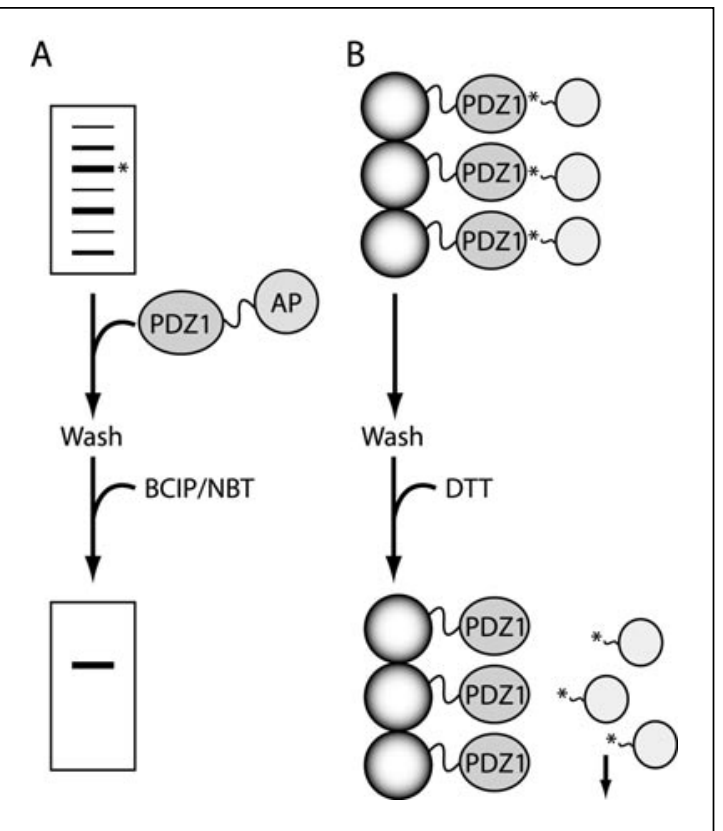

Figure 1. Schematic detailing protein purification and detection uses for the NorpA tag. (A) A protein labeled with the NorpA C-terminal residues (denoted by *) can be detected from a pool of other proteins by incubation with a PDZ1-alkaline phosphatase fusion, followed by washing and the addition of an alkaline phosphatase substrate (BCIP/NBT). (B) A NorpA-tagged protein $(*)$ can be purified from a pool of other proteins by incubating lysate with immobilized PDZ1. Non-tagged proteins are eluted in the wash step, and the NorpA-tagged protein are eluted with the addition of a reducing agent to break the disulfide bond. mant and digested with $K p n I$ and $B g l I I$. The purified insert was ligated into UANTagen $(\mathrm{kx})\left(\mathrm{PhoA}^{*}\right.$ Color $^{\mathrm{TM}}$ Sys, Qbiogene, Montreal, QC, Canada), line phosphatase was expressed by transforming pQUANT/PDZ1 into XL1Blue ${ }^{\circledR}$ E. coli (Stratagene) and inducing it with $0.5 \mathrm{mM}$ IPTG, according to the manufacturer's protocol.

\section{Surface Plasmon Resonance}

Biotinylated peptides that corresponded to the C-terminal 12 residues of NorpA (UNC Microprotein Sequencing and Peptide Synthesis Facility, Chapel Hill, NC, USA) were loaded to a streptavidin-coated surface plastions of purified PDZ1 were injected in for $75 \mathrm{~s}$. Between succc ensurements, the surfaces were regenerated with DTT-containing regeneration buffer at $20 \mu \mathrm{L} / \mathrm{min}$. Background-corrected sensorgrams were fit to a single-site binding model using the numerical integration function of BIAevaluation $^{\circledR} \quad 3.2$ software (BIAcore AB, Uppsala, Sweden). The observed rate constant $\left(\mathrm{k}_{\mathrm{obs}} \mathrm{s}^{-1}\right)$ was derived from a least-squares minimization of the fit to the association phase of the sensorgrams to a 1:1 Langmuir binding equation. The association rate constant, $\mathrm{k}_{\mathrm{on}}\left(\mathrm{M}^{-1} \mathrm{~s}^{-1}\right)$, was determined as the slope of the line $\mathrm{k}_{\mathrm{obs}}$ versus PDZ1.

\section{PDZ1-Alkaline Phos- phatase Blot Analysis}

E. coli samples expressing Goil or Goil-NorpA before and after induction were lysed in denaturing sample buffer and resolved by $15 \%$ SDS-PAGE. The samples were standardized using the Bio-Rad ${ }^{\circledR}$ Protein Assay (Bio-Rad Laboratories, Hercules, CA, USA) to ensure the equal protein loading of in each lane $(33.9 \mu \mathrm{g})$. (In the case of $\mathrm{CT}_{\text {Dm }}$, purified $\mathrm{CT}_{\mathrm{Dm}}$ was added to uninduced $E$. coli lysates, which were subjected to SDS/PAGE as described earlier.) Separated proteins were transferred to nitrocellulose membranes using a tank transfer system (Trans-Blot ${ }^{\circledR}$ Cell; Bio-Rad Laboratories).

Nitrocellulose membranes were blocked, washed, and incubated with 1 $\mathrm{mL}$ purified PDZ1-AP in $10 \mathrm{~mL} \mathrm{5 \%}$ milk/TBST for $4 \mathrm{~h}$ at room temperature. The membranes were washed again and incubated with 5-bromo-4chloro-3-indolyl phosphate/nitro blue tetrazolium (BCIP/NBT) (Sigma, St. Louis, MO, USA) for $10 \mathrm{~min}$. After BCIP/NBT development, some membranes were stained for total protein with a solution of $0.1 \%(\mathrm{w} / \mathrm{v})$ Amido Black 10B ${ }^{\circledR}$ (Bio-Rad Laboratories).

\section{Western Blot Analysis}

To test for equivalent Goi1 and Goil-NorpA levels, E. coli samples that

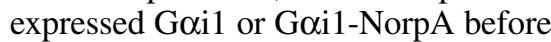
and after induction were subjected to SDS-PAGE and transferred to nitrocellulose as described earlier for PDZ1-alkaline phospatase blot analysis. The membrane was blocked and immunoblotted with a rabbit anti-Goi1 antibody that recognizes the specific Goil sequence CLDRIAQPNYI (Biodesign International, Saco, ME, USA) at a 1:1000 dilution in $5 \%$ milk/TBST. The membrane was washed and immunoblotted with a 1:2000 dilution of anti-rabbitHRP antibody (Amersham Biosciences, Piscataway, NJ, USA). After a final wash, the membrane was developed with $\mathrm{ECL}^{\mathrm{TM}}$ western blotting reagents (Amersham Biosciences).

To show that PDZ1 blots can be stripped and reused, E. coli samples expressing Goi1-NorpA, with $2.5 \mu \mathrm{g}$ purified GST added as a control, were subjected to SDS-PAGE and transferred to nitrocellulose membranes. The membrane was blocked and incubated with $\mathrm{His}_{6}$-PDZ1 for $4 \mathrm{~h}$, washed, and incubated with a 1:1000 dilution of a rabbit anti-His ${ }_{6}$ antibody (Covance, Princeton, NJ, USA). The membrane was developed with the ECL system. Immediately following development, the membrane was washed with $10 \mathrm{mM}$ 
DTT in TBS and a final wash in TBS alone. The membrane was blocked and incubated with a 1:1000 dilution of a mouse anti-GST antibody (Sigma). The incubation with an anti-mouse-HRP antibody (Amersham Biosciences) allowed for development with ECL.

\section{Goi1 Affinity Purification}

Purified $\mathrm{His}_{6}$-PDZ1 (8 mg) was coupled with $5 \mathrm{~mL}$ NHS-activated Sepharose ${ }^{\circledR}$ (Amersham Biosciences) for $3 \mathrm{~h}$ at room temperature. The Sepharose was deactivated by incubation in $0.5 \mathrm{M}$ ethanolamine for $3 \mathrm{~h}$, followed by alternating washes in $25 \mathrm{mM}$ Tris- $\mathrm{HCl}, \mathrm{pH} 8.0$, and $50 \mathrm{mM}$ sodium acetate, $\mathrm{pH}$ 3.0. The beads were equilibrated in binding buffer $[10 \mathrm{mM}$ $\mathrm{Na}_{2} \mathrm{HPO}_{4}, 10 \mathrm{mM} \mathrm{NaH} \mathrm{PO}_{4}, 500 \mathrm{mM}$ $\mathrm{NaCl}, 0.1 \%$ (w/v) SDS, $1 \%$ (v/v) Nonidet $^{\mathrm{TM}} \mathrm{P}-40,0.5 \%(\mathrm{w} / \mathrm{v})$ sodium deoxycholate, $10 \mathrm{mM}$ oxidized glutathione].
Soluble lysate from a 100-mL E. coli

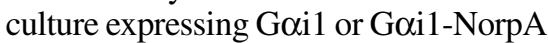
was incubated with $1 \mathrm{~mL}$ nickel agarose or $1 \mathrm{~mL}$ PDZ1-coupled sepharose, respectively, for $30 \mathrm{~min}$ at room temperature. The beads were washed twice with 20 column volumes nickel buffer A (20 $\mathrm{mM}$ sodium phosphate, $\mathrm{pH} 7.5,150$ $\mathrm{mM} \mathrm{NaCl}, 10 \mathrm{mM}$ imidazole, $10 \%$ glycerol) or PDZ1 binding buffer. Goi1 or Goil-NorpA was eluted with nickel buffer B (buffer A + imidazole) or PDZ1 elution buffer (binding buffer + DTT). Samples from each purification step were separated by SDS-PAGE. Gels were stained with Silver Stain Plus ${ }^{\circledR}$ (Bio-Rad Laboratories).

\section{RESULTS}

\section{Wild-Type NorpA Sequence Is Optimized for PDZ1 Binding}

To demonstrate that PDZ1 specifi- cally interacts with the wild-type NorpA sequence, surface plasmon resonance studies were conducted in which $\mathrm{N}$-terminally biotinylated NorpA peptides were immobilized on a streptavidin-coated surface plasmon resonance chip, followed by injections of various concentrations of purified PDZ1. The results indicate that only cysteine-containing peptides, both wild-type (Figure 2A; EFCA) and mutant (Figure 2B; EACA) elicit a concentration-dependent binding response to PDZ1. Because the dissociation rate constant $\left(\mathrm{k}_{\mathrm{off}}\right)$ of a covalent interaction is zero, the affinity of the interaction, which is usually communicated as the equilibrium dissociation constant $\mathrm{K}_{\mathrm{D}}\left(\mathrm{k}_{\text {off }} / \mathrm{k}_{\mathrm{on}}\right)$, is zero, regardless of the value of the association rate constant $\left(\mathrm{k}_{\mathrm{on}}\right)$. Therefore, $\mathrm{k}_{\text {on }}\left(\mathrm{M}^{-1} \mathrm{~s}^{-1}\right)$ is the only meaningful value for the comparison of PDZ1 binding to NorpA peptides. When $\mathrm{k}_{\mathrm{on}}$ is calculated for the cysteine-containing pep- 
Table 1. Calculated Affinities of PDZ1 for Wild-Type and Mutant NorpA Peptides

\begin{tabular}{|c|c|}
\hline C-Terminal Sequence & $\mathrm{k}_{\text {on }}\left(\mathrm{M}^{-1} \mathrm{~s}^{-1}\right)$ \\
\hline EFCA & 563.5 \\
\hline EÁCA & 1.35 \\
\hline EF $\underline{S} A$ & none \\
\hline EF $\underline{A} A$ & none \\
\hline \multicolumn{2}{|c|}{$\begin{array}{l}\mathrm{k}_{\mathrm{on}}\left(\mathrm{M}^{-1} \mathrm{~s}^{-1}\right) \text { was determined by a least-squares linear fit of } \mathrm{k}_{\mathrm{obs}}\left(\mathrm{s}^{-1}\right) \text { versus the } \\
\text { PDZ1 concentration (M). EF } \underline{S} A \text { and EFAA demonstrate no binding to PDZ1; } \\
\text { therefore, } \mathrm{k}_{\mathrm{on}} \text { is not calculated (indicated by "none"). }\end{array}$} \\
\hline
\end{tabular}

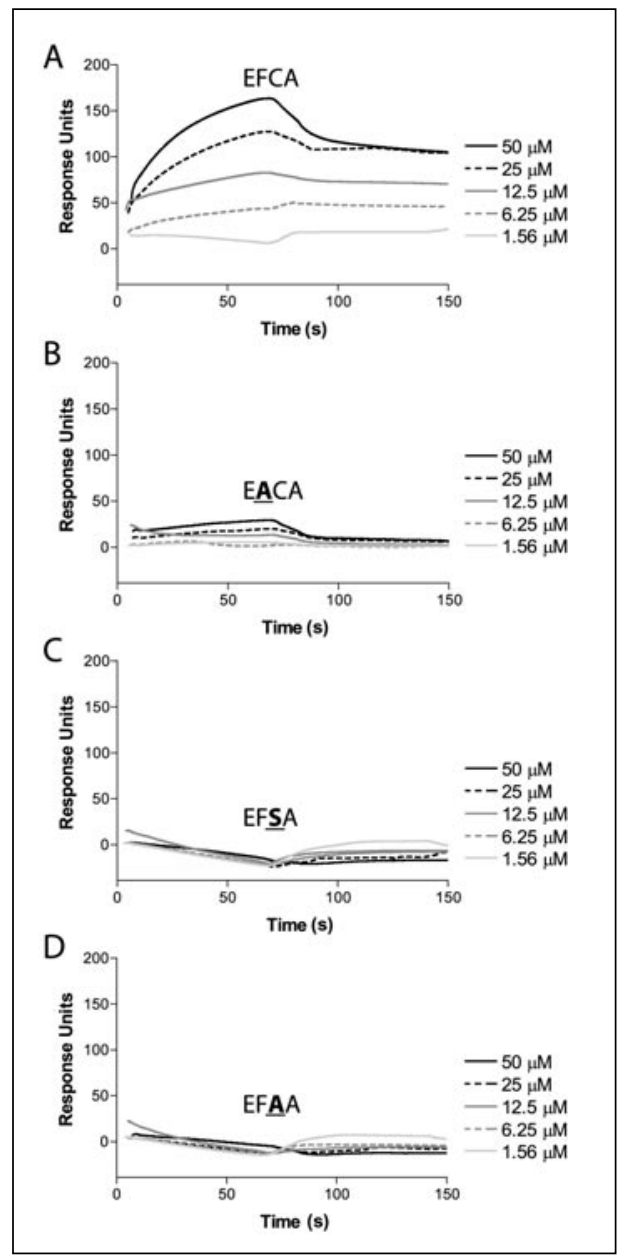

Figure 2. PDZ1 binds with high affinity to wild-type NorpA peptide but not to mutants. (A) A biotinylated peptide that corresponds to the $\mathrm{C}$-terminal 12 residues of NorpA (EFCA) was immobilized on a streptavidincoated surface plasmon resonance chip and various concentrations of PDZ1 flowed over. The wild-type NorpA peptide shows a strong concentration-dependent binding response to PDZ1. (B) A peptide that corresponded to a Phe-to-Ala mutation (EACA) exhibits a weak concentration-dependent binding response to PDZ1. (C) PDZ1 did not exhibit any binding to a peptide that corresponded to an isosteric Cys-to-Ser mutation (EF $\underline{\mathbf{S}} \mathrm{A})$. The sensorgram was nearly identical to panel $\mathrm{D}$, where the immobilized peptide corresponded to a Cys-to-Ala mutation (EFAA). tides EFCA and EACA, a 400-fold decrease in affinity is observed for the mutation of Phe $(-2)$ to Ala $\left(\mathrm{k}_{\mathrm{on}}=\right.$ $563.5 \mathrm{M}^{-1} \mathrm{~s}^{-1}$ and $1.35 \mathrm{M}^{-1} \mathrm{~s}^{-1}$, respectively) (Table 1). The disulfide bond is clearly the most important interaction, though, since the mutation of Cys(-1) to Ser or Ala completely abolishes binding (Figure 3 , $\mathrm{C}$ and D, EFSA and EFAA). In addition, cysteine hydrogen-bonding plays no part in the NorpA/PDZ1 interaction because the isosteric Cysto-Ser mutation had the same effect as the nonconservative Cys-to-Ala mutation. These results indicate that the wild-type NorpA sequence is optimized for PDZ1 binding, which is important because a motif search of the Swiss-Prot database (http:// motif.genome.ad.jp/) reveals that only five other proteins have the same three C-terminal residues as NorpA (F-C-A-COO-). Even a more general $\Phi-\mathrm{C}-\Phi-\mathrm{COO}^{-}$sequence only occurs in 200 different proteins in the Swiss-Prot database.

\section{PDZ1-Alkaline Phosphatase Binds to $\mathrm{CT}_{\mathrm{Dm}}$ Specifically}

To show that PDZ1-alkaline phosphatase can be used to specifically detect its physiological ligand from a pool of other proteins, varying amounts of purified $\mathrm{CT}_{\mathrm{Dm}}$ were added to BL21 (DE3) whole-cell lysate $(33.9 \mu \mathrm{g}$ lysate protein) and separated by PAGE, along with a control lane of purified $\mathrm{CT}_{\mathrm{Dm}}$ without lysate. Protein bands were transferred to a nitrocellulose membrane, blocked, and incubated with PDZ1-alkaline phosphatase for $4 \mathrm{~h}$. After we had washed the membrane extensively, it was developed with BCIP/NBT. Fifty nanograms of $\mathrm{CT}_{\mathrm{Dm}}$ are faintly detected out of $33.9 \mu \mathrm{g}$ total cellular protein $\left(\mathrm{CT}_{\mathrm{Dm}}\right.$ less than 1/600th total protein), while $100 \mathrm{ng}$ are clearly detected by PDZ1-alkaline phosphatase (Figure $3 \mathrm{~A}$ ). Since $\mathrm{CT}_{\mathrm{Dm}}$ alone does not react with BCIP/NBT (data not shown), any color change is a result of bound PDZ1-alkaline phosphatase. Additionally, because no other bands react with BCIP/NBT, PDZ1-alkaline phosphatase interacts specifically with $\mathrm{CT}_{\mathrm{Dm}}$, even in a background of cellular lysate (Figure 3B).

\section{Addition of the NorpA Tail Confers PDZ1 Binding to Heterologous Proteins}

The C-terminal five residues of NorpA were spliced onto Goil, a signaling protein that does not normally interact with PDZ1, to demonstrate that the addition of these residues is sufficient to confer PDZ1-binding ability. Bacterial samples that expressed either Goi1 or Goi1-NorpA were separated by gel electrophoresis and transferred to a nitrocellulose membrane, along with purified $\mathrm{CT}_{\mathrm{Dm}}$ as a positive control. As previously described for $\mathrm{CT}_{\mathrm{Dm}}$ (Figure 3 ), the membrane was blocked, incubated with PDZ1-alkaline phosphatase, washed, and developed with BCIP/ NBT. PDZ1-alkaline phosphatase specifically detects Goil-NorpA but not untagged Goil (Figure 4A) even in a background of cellular lysate (Figure 4B). As a control for Goil expression, a duplicate blot was probed with a rabbit anti-Goi1 primary antibody, followed by an anti-rabbit HRP-conjugated secondary antibody. A chemiluminescent assay clearly shows that Goil and Goi1-NorpA were both similarly expressed at high levels (Figure 4C).

\section{PDZ1 Bound to a NorpA-Tagged Protein Is Easily Dissociable}

There are several protocols for stripping antibodies from membranes to reprobe, but most involve high temperature $\left(70^{\circ} \mathrm{C}\right)$, detergents (SDS), high concentrations of denaturants $[200 \mathrm{mM}$ $\beta$-mercaptoethanol ( $\beta$-ME)], and may not be reproducible. To demonstrate further the usefulness of the NorpA tag as a protein detection tool, Goi1-expressing 
E. coli cell lysates spiked with $2.5 \mu \mathrm{g}$ purified GST were resolved by SDSPAGE, transferred to nitrocellulose membranes, and incubated with $\mathrm{His}_{6-}$ PDZ1. The PDZ1/Goil-NorpA interaction was detected by immunoblotting with a rabbit anti-His ${ }_{6}$ primary antibody, followed by an anti-rabbit-HRP secondary antibody (Figure 5, left panel). PDZ1 was then stripped from the membrane by the addition of $10 \mathrm{mM}$ DTT to the TBS wash step. The membrane was incubated with a mouse anti-GST primary antibody, followed by an anti-mouseHRP secondary antibody. After chemiluminescent analysis, there was no residual signal from the anti-rabbit-HRP antibody (Figure 5, middle panel), which indicated that the entire PDZ1/anti-His 6 antibody/anti-rabbit-HRP antibody complex was stripped from the membrane [along with the nonspecific bands typical of anti-His 6 antibody, which is quite promiscuous (6)]. In addition, the mild stripping conditions leave the membrane amenable to re-probing with anti-GST antibody. Amido Black staining shows the total protein content of the membrane after both immunoblotting experiments (Figure 5, right panel).

\section{Immobilized PDZ1 Can Purify Goi1-NorpA from Cell Lysate}

To demonstrate that the NorpA tag is useful for protein purification, we immobilized PDZ1 on NHS-activated sepharose and incubated the beads with the soluble fraction of the E. coli cell lysate expressing Goil-NorpA. The beads were washed extensively, and the bound Goil-NorpA was eluted with various concentrations of DTT. Samples of subsequent Goil-NorpA purification steps from control beads and PDZ1-coupled beads were resolved by SDS-PAGE and silver-stained for total protein. Goi1-NorpA shows very little nonspe- cific binding to blank beads (data not shown). Coupling PDZ1 with the beads allows for the binding and elution of Goi1-NorpA with increasing concentrations of DTT, with most of the bound Goil-NorpA eluted with $50 \mathrm{mM}$ DTT. (Figure 6A). The identity of the predominant band in the elution fractions as Goi1 was confirmed by immunoblotting with an anti-Goil antibody (data not shown). The Goi1-NorpA in the elution fractions is approximately $85 \%$ purified compared to the initial sample. This is compared to $\mathrm{His}_{6}$-Goil purified by conventional $\mathrm{Ni}^{2+}$ affinity chromatography (Figure 6B), where the overall yield of purified protein in the elution fractions is greater but much less pure.

\section{DISCUSSION}

The optimization of the NorpA tag and PDZ1 detection system should 


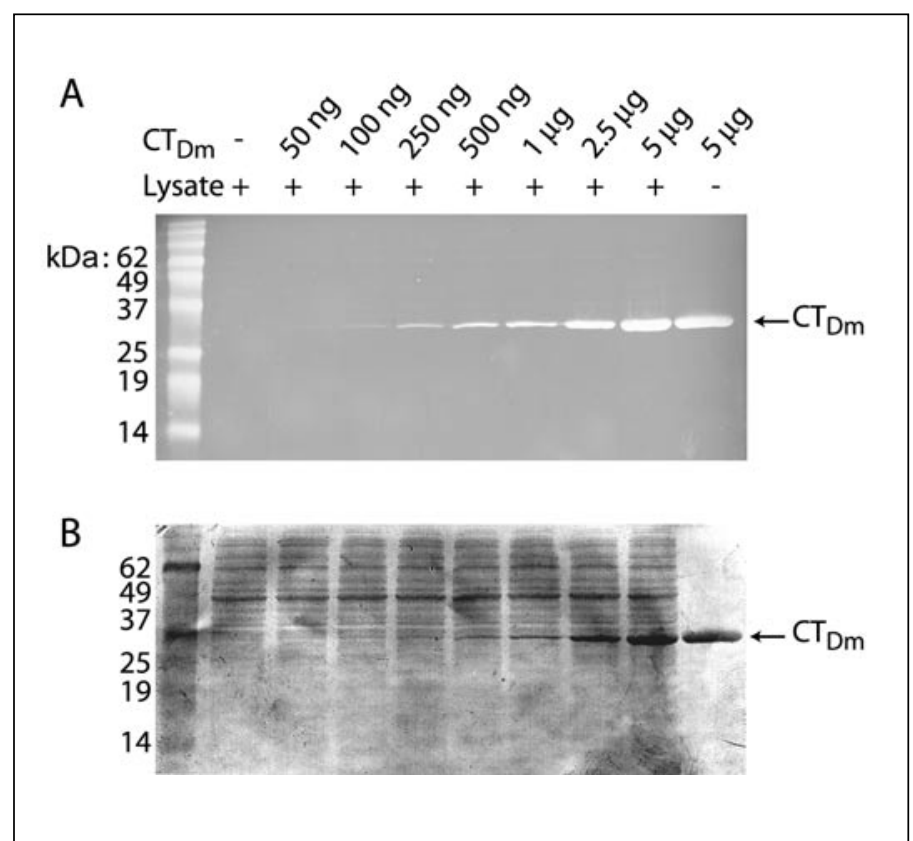

Figure 3. PDZ1-alkaline phosphatase specifically detects $\mathbf{C T}_{\mathrm{Dm}}$ in a background of bacterial proteins. (A) Varying amounts of purified $\mathrm{CT}_{\mathrm{Dm}}$ were added to BL21(DE3) samples and separated by SDS-PAGE, followed by transfer to nitrocellulose membranes. The membrane was blocked and incubated with PDZ1alkaline phosphatase for $4 \mathrm{~h}$, followed by extensive washing. The color change of the $\mathrm{CT}_{\mathrm{Dm}}$ band after the addition of BCIP/NBT indicates that PDZ1-alkaline phosphatase interacts specifically with $\mathrm{CT}_{\mathrm{Dm}}$ in a background of bacterial proteins. (B) The same membrane as in panel A was stained for total protein with an Amido Black solution.

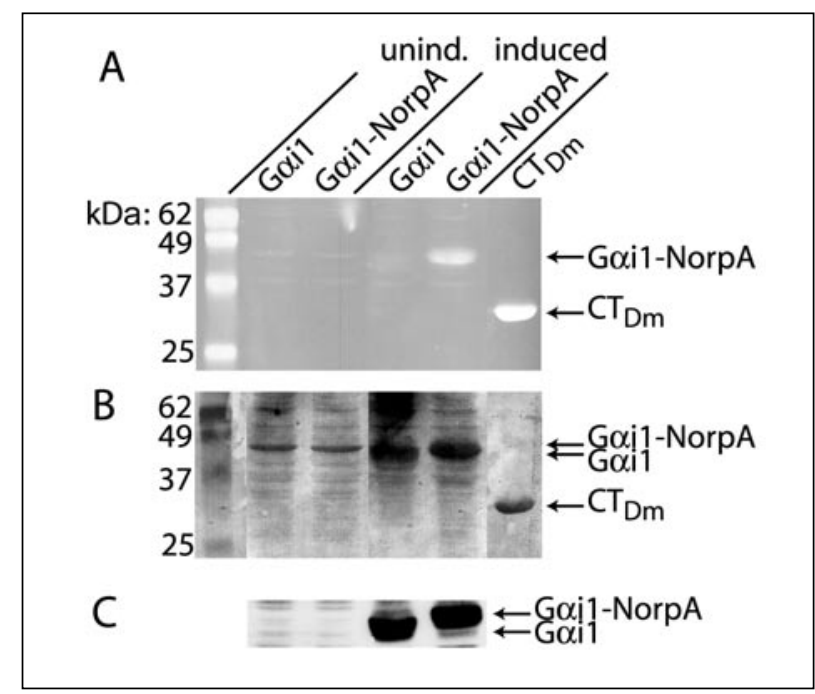

Figure 4. PDZ1-alkaline phosphatase specifically detects Goi1-NorpA in a background of bacterial proteins. (A) E. coli cells expressing Goi1 or Goil-NorpA before and after induction were lysed in SDS sample buffer, and the proteins were separated by denaturing PAGE, followed by transfer to nitrocellulose membranes. Purified $\mathrm{CT}_{\mathrm{Dm}}$ was used as a positive control. The membrane was incubated with PDZ1-alkaline phosphatase for $4 \mathrm{~h}$, followed by extensive washing. The color change of the Goil-NorpA band after the addition of BCIP/NBT indicates that PDZ1alkaline phosphatase specifically interacts with Goil-NorpA in a background of bacterial proteins but not with Goil alone. (B) Identical membrane as in panel A, stained with Amido Black to show the total protein species. (C) Western blot analysis of a duplicate nitrocellulose membrane to show equivalent amounts of Goil and Goil-NorpA. Lanes are identical to those in panel A. The membrane was incubated with rabbit antiGoil with an internal recognition sequence, followed by incubation with $\alpha$-rabbit-HRP to detect Goil by chemiluminescence.

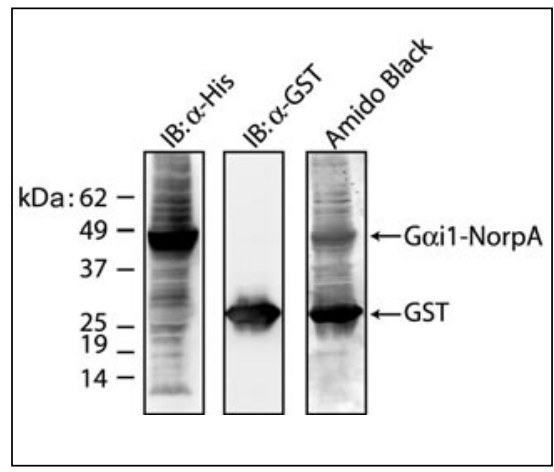

Figure 5. Membranes incubated with PDZ1 can be easily stripped and reused. A Goil-NorpA-expressing $E$. coli sample was spiked with 2.5 $\mu \mathrm{g} \mathrm{GST}$, lysed in SDS sample buffer, and the proteins were separated by SDS-PAGE, followed by transfer to nitrocellulose membranes. The membrane was incubated with $\mathrm{His}_{6}$-PDZ1 for $4 \mathrm{~h}$, washed, and immunoblotted with anti-His ${ }_{6}$ to detect Goi1-NorpA through its interaction with His $_{6}$-PDZ1 (left panel). The complete removal of the $\mathrm{His}_{6}$-PDZ1/rabbit anti-His 6 antibody/antirabbit-HRP antibody complex was attained by washing the membrane in a reducing buffer, as evidenced by subsequent immunoblotting with anti-GST (center panel). After all immunoblots were completed, the membrane was stained for total protein with Amido Black (right panel).

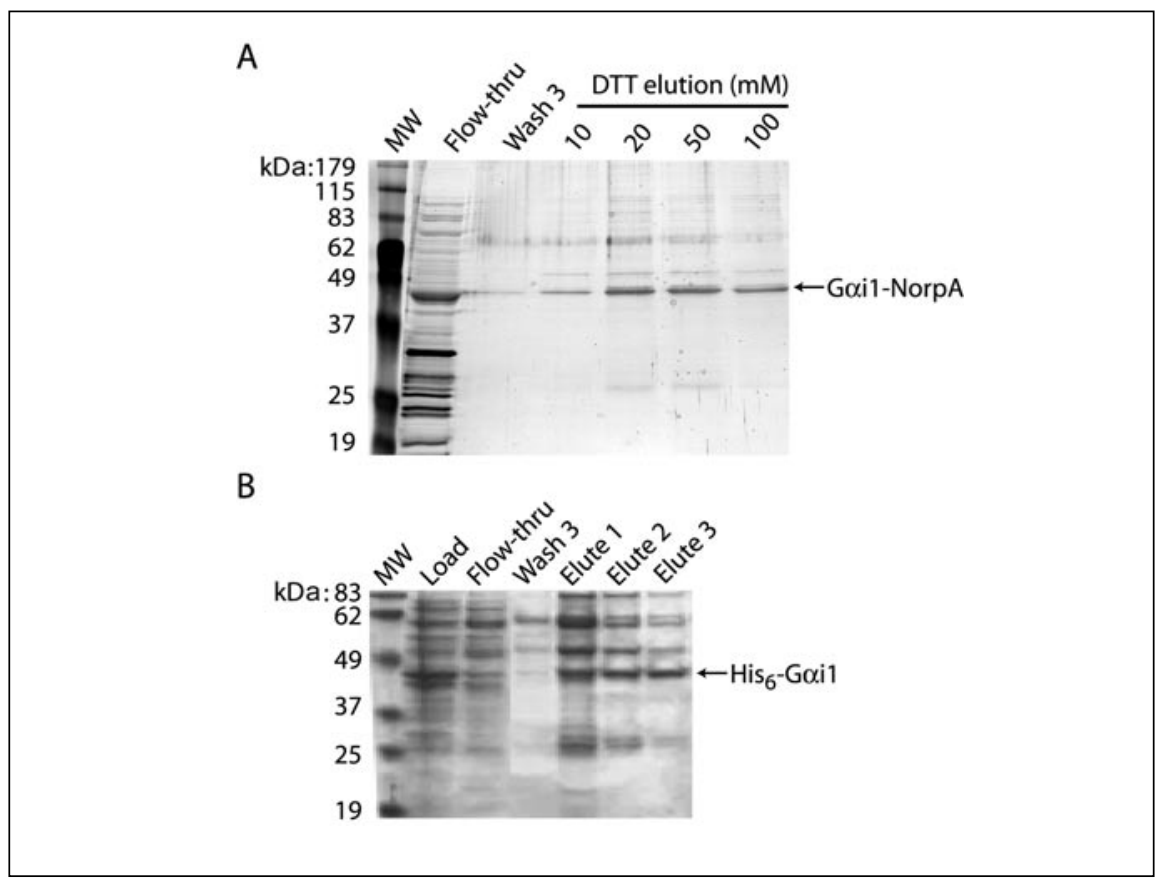

Figure 6. Immobilized PDZ1 can purify Gai1-NorpA from bacterial lysate. (A) PDZ1-coupled beads can bind Goil-NorpA, which is specifically eluted by DTT, as shown by silver staining. (B) As shown by Coomassie ${ }^{\circledR}$ stain, $\mathrm{His}_{6}$-Goil that was purified by $\mathrm{Ni}^{2+}$ agarose was not as enriched in the elution fractions as when it was purified by PDZ1 affinity chromatography. 


\begin{tabular}{|c|c|c|c|c|c|c|c|c|}
\hline \multirow[b]{2}{*}{ Affinity Tag } & \multirow{2}{*}{$\begin{array}{l}\text { MW } \\
(k D a)\end{array}$} & \multicolumn{2}{|c|}{ Use } & \multirow[b]{2}{*}{ Ligand } & \multirow[b]{2}{*}{ Elution } & \multirow[b]{2}{*}{ Other Advantages } & \multirow[b]{2}{*}{ Other Disadvantages } & \multirow[b]{2}{*}{ Other Uses } \\
\hline & & Detection & Purification & & & & & \\
\hline c-Myc & 1.2 & yes & yes $^{b}$ & $\begin{array}{l}\text { Immobilized } \\
\text { anti-c-Myc }\end{array}$ & High pH & $\begin{array}{l}\text { Tag at } \mathrm{N} \text { - or } \mathrm{C} \text {-term; } \\
\text { linear recognition }\end{array}$ & $\begin{array}{l}\text { anti-c-Myc } \\
\text { promiscuous; Low pH } \\
\text { elution may cause } \\
\text { aggregation }\end{array}$ & $\begin{array}{l}\text { Protein-protein } \\
\text { interactions, esp. } \\
\text { IP/IB }\end{array}$ \\
\hline $\begin{array}{l}\text { Hemagglutinin } \\
\text { (HA) }\end{array}$ & 3.5 & yes & yes $^{b}$ & $\begin{array}{l}\text { Immobilized } \\
\text { anti-HA }\end{array}$ & $\begin{array}{l}\text { Free HA } \\
\text { peptide }\end{array}$ & $\begin{array}{l}\text { N- or C-term; linear } \\
\text { recognition; anti-HA } \\
\text { specific }\end{array}$ & & $\begin{array}{l}\text { Protein-protein } \\
\text { interactions, esp. } \\
\text { IP/IB, ELISA }\end{array}$ \\
\hline GFP & 31.0 & yes & no & $\mathrm{N} / \mathrm{A}$ & $\mathrm{N} / \mathrm{A}$ & $\begin{array}{l}\text { Tag at N- or C-term; } \\
\text { anti-GFP specific; } \\
\text { GFP is fluorescent }\end{array}$ & $\begin{array}{l}\text { Very large tag; some } \\
\text { GFP fusions non- } \\
\text { specifically targeted } \\
\text { to nucleus }\end{array}$ & $\begin{array}{l}\text { Protein-protein } \\
\text { interactions, esp. } \\
\text { immuno- } \\
\text { colocalization }\end{array}$ \\
\hline GST & 28.0 & yes & yes & $\begin{array}{l}\text { Immobilized } \\
\text { glutathione }\end{array}$ & $\begin{array}{l}\text { Reduced } \\
\text { glutathione }\end{array}$ & $\begin{array}{l}\text { Tag at N- or C-term; } \\
\text { anti-GST specific }\end{array}$ & $\begin{array}{l}\text { Very large tag; GST } \\
\text { dimerizes and is highly } \\
\text { antigenic; glutathione } \\
\text { may affect disulfide- } \\
\text { containing proteins }\end{array}$ & $\begin{array}{l}\text { Protein-protein } \\
\text { interactions, esp. } \\
\text { pull-down assays, } \\
\text { IP/IB }\end{array}$ \\
\hline $\mathrm{His}_{6}$ & $0.8-3.0^{a}$ & yes & yes & $\begin{array}{l}\text { Immobilized } \\
\mathrm{Ni}^{2+}\end{array}$ & $\begin{array}{l}\text { Low } \mathrm{pH} \text {, } \\
\text { imidazole, } \\
\text { or EDTA }\end{array}$ & $\begin{array}{l}\text { Tag at } \mathrm{N} \text { - or } \mathrm{C}- \\
\text { terminus; linear } \\
\text { recognition; native or } \\
\text { denatured protein } \\
\text { purification }\end{array}$ & $\begin{array}{l}\text { Nonspecific binding } \\
\text { to } \mathrm{Ni}^{2+} \text {; anti-His } \\
\text { promiscuous; } \mathrm{pH} \text { or } \\
\text { imidazole may cause } \\
\text { aggregation }\end{array}$ & $\begin{array}{l}\text { Protein-protein } \\
\text { interactions, esp. } \\
\text { pull-down assays }\end{array}$ \\
\hline $\begin{array}{l}\text { aLength depen } \\
\text { bNon- or semi- } \\
\text { cExamples of } p \\
\text { immuno-coloc }\end{array}$ & $\begin{array}{l}\text { nds on clo } \\
\text {-reusable } \\
\text { protein-pr } \\
\text { calization, }\end{array}$ & $\begin{array}{l}\text { oning vector } \\
\text { affinity resi } \\
\text { rotein intere } \\
\text {, and surfac }\end{array}$ & $\begin{array}{l}r \\
\text { ins } \\
\text { action assays i } \\
\text { ce plasmon res }\end{array}$ & $\begin{array}{l}\text { lude but are } n \\
\text { hance (SPR). }\end{array}$ & ited to immu & cipitation/immunob & (IP/IB), affinity pull-dow & ssays, ELISAs, cell \\
\hline
\end{tabular}


yield a powerful tool for protein purification and detection that improves on currently available methods. Table 2 shows a summary of several characteristics of the NorpA tag, as compared with commonly used affinity and epitope tags $(2,6,8,13,16,18)$.

Two affinity tags are used regularly for both protein detection and purification, GST and $\mathrm{His}_{6}(2,16,18)$. Both GST and $\mathrm{His}_{6}$ tags are quite useful for protein-protein interaction assays such as immunoprecipitation/immunoblotting, ELISAs, cell immuno-colocalization, and surface plasmon resonance; however, both have disadvantages. The $28-\mathrm{kDa}$ GST tag is sometimes larger than the protein or peptide of interest, and it readily homodimerizes, which can lead to experimental artifacts. Conversely, His $_{6}$ tags can be as short as six residues, depending on the expression vector, but anti-His ${ }_{6}$ antibodies are notoriously promiscuous and may require additional residues for specificity.

In comparison, the five-residue NorpA tag is shorter than any of the commonly used affinity tags and is useful for both protein purification and detection. PDZ1 binds specifically and covalently to the NorpA C-terminus (Figures 2-4) and is dissociable with the addition of a reducing agent such as DTT (Figure 5). In addition, the development of a PDZ1alkaline phosphatase fusion that can detect NorpA-tagged proteins negates the necessity of primary antibody generation, although an HRP-PDZ1 fusion would be useful for sensitive chemiluminescent detection of NorpA-tagged protein. The NorpA tag can also be used to purify proteins via immobilized PDZ1 (Figure 6). Optimization of the purification protocols, such as the addition of a flexible linker to PDZ1 and different coupling chemistries, could yield a moderately reusable, high-affinity resin comparable to glutathione sepharose. This would make the NorpA C-terminus one of the most useful affinity tags, comparable with the $\mathrm{His}_{6}$ tag in length but potentially more useful for protein detection because of the specific, high-affinity interaction of NorpA with PDZ1. Specifically, the covalent interaction between PDZ1 and NorpA is ideal for protein-protein interaction techniques such as surface plasmon resonance, where a strong attachment of the protein of interest to the biosensor chip is required, but the covalent attachment of proteins via primary amino groups can sometimes result in the loss of biological activity. A PDZ1 surface would "catch" NorpA-tagged proteins, which would then be analyzed for their binding to various ligands. The entire surface could be regenerated by flowing over a reducing buffer, which would allow the covalent attachment of a different NorpA-tagged protein for a new set of binding experiments.

\section{ACKNOWLEDGMENTS}

We would like to thank Minh T. Pham and Svetlana Gershburg for technical assistance and Dr. David P. Siderovski and Randall J. Kimple for thoughtful discussions and critical reading of the manuscript. This work was funded in part by National Institutes of Health grant no. GM57391 to J.S., the Pew Charitable Trusts, and the Program in Molecular and Cellular Biophysics at UNC-CH (M.E.K.).

\section{REFERENCES}

1.Bahner, M., P. Sander, R. Paulsen, and A. Huber. 2000. The visual G protein of fly photoreceptors interacts with the PDZ domain assembled INAD signaling complex via direct binding of activated $\mathrm{Ga}_{\mathrm{q}}$ to phospholipase C-b. J. Biol. Chem. 275:2901-2904.

2.Bornhorst, J.A. and J.J. Falke. 2000. Purification of proteins using polyhistidine affinity tags. Methods Enzymol. 326:245-254.

3.Chevesich, J., A.J. Kreuz, and C. Montell. 1997. Requirement for the PDZ domain protein, INAD, for localization of the TRP storeoperated channel to a signaling complex. Neuron 18:95-105.

4.Daniels, D.L., A.R. Cohen, J.M. Anderson, and A.T. Brunger. 1998. Crystal structure of the hCASK PDZ domain reveals the structural basis of class II PDZ domain target recognition. Nat. Struct. Biol. 5:317-325.

5.Doyle, D.A., A. Lee, J. Lewis, E. Kim, M. Sheng, and R. MacKinnon. 1996. Crystal structures of a complexed and peptide-free membrane protein-binding domain: molecular basis of peptide recognition by PDZ. Cell 85:1067-1076.

6.Fritze, C.E. and T.R. Anderson. 2000. Epitope tagging: general method for tracking recombinant proteins. Methods Enzymol. 327:3-16.

7.Hillier, B.J., K.S. Christopherson, K.E. Prehoda, D.S. Bredt, and W.A. Lim. 1999. Unexpected modes of PDZ domain scaffolding revealed by structure of nNOS-syntrophin complex. Science 284:812-815.

8.Jones, C., A. Patel, S. Griffin, J. Martin, P. Young, K. O'Donnell, C. Silverman, T. Por- ter, and I. Chaiken. 1995. Current trends in molecular recognition and bioseparation. J. Chromatogr. A 707:3-22.

9.Kennedy, M.B. 1995. Origin of PDZ (DHR, GLGF) domains. Trends Biochem. Sci. 20:350.

10.Kimple, M.E., D.P. Siderovski, and J. Sondek. 2001. Functional relevance of the disulfide-linked complex of the N-terminal PDZ domain of InaD with NorpA. EMBO J. 20:4414-4422.

11.Kimple, R.J., L. De Vries, H. Tronchere, C.I. Behe, R.A. Morris, M. Gist Farquhar, and D.P. Siderovski. 2001. RGS12 and RGS14 GoLoco motifs are $\mathrm{G} \alpha_{i}$ interaction sites with guanine nucleotide dissociation inhibitor activity. J. Biol. Chem. 276:29275-29281.

12.Morais Cabral, J.H., C. Petosa, M.J. Sutcliffe, S. Raza, O. Byron, F. Poy, S.M. Marfatia, A.H. Chishti, et al. 1996. Crystal structure of a PDZ domain. Nature 382:649-652.

13.Nilsson, J., S. Stahl, J. Lundeberg, M. Uhlen, and P.A. Nygren. 1997. Affinity fusion strategies for detection, purification, and immobilization of recombinant proteins. Protein Expr. Purif. 11:1-16.

14.Scott, K., A. Becker, Y. Sun, R. Hardy, and C. Zuker. 1995. $\mathrm{G}_{\mathrm{q}} \alpha$ protein function in vivo: genetic dissection of its role in photoreceptor cell physiology. Neuron 15:919-927.

15.Scott, K. and C.S. Zuker. 1998. Assembly of the Drosophila phototransduction cascade into a signaling complex shapes elementary responses. Nature 395:805-808.

16.Sheibani, N. 1999. Prokaryotic gene fusion expression systems and their use in structural and functional studies of proteins. Prep. Biochem. Biotechnol. 29:77-90.

17.Shieh, B.H., M.Y. Zhu, J.K. Lee, I.M. Kelly, and F. Bahiraei. 1997. Association of INAD with NORPA is essential for controlled activation and deactivation of Drosophila phototransduction in vivo. Proc. Natl. Acad. Sci. USA 94:12682-12687.

18.Smith, D.B. 2000. Generating fusions to glutathione S-transferase for protein studies. Methods Enzymol. 326:254-270.

19.Tsunoda, S., J. Sierralta, Y. Sun, R. Bodner, E. Suzuki, A. Becker, M. Socolich, and C.S. Zuker. 1997. A multivalent PDZ-domain protein assembles signaling complexes in a G-protein-coupled cascade. Nature 388:243-249.

20.van Huizen, R., K. Miller, D.M. Chen, Y. Li, Z.C. Lai, R.W. Raab, W.S. Stark, R.D. Shortridge, et al. 1998. Two distantly positioned PDZ domains mediate multivalent INAD-phospholipase $\mathrm{C}$ interactions essential for $\mathrm{G}$ proteincoupled signaling. EMBO J. 17:2285-2297.

21.Xu, X.Z., A. Choudhury, X. Li, and C. Montell. 1998. Coordination of an array of signaling proteins through homo- and heteromeric interactions between PDZ domains and target proteins. J. Cell Biol. 142:545-555.

Received 4 April 2002; accepted 20 May 2002.

Address correspondence to:

Dr. John Sondek

UNC-CH Department of Pharmacology, CB\# 7365

Chapel Hill, NC 27599-7365, USA

e-mail:sondek@med.unc.edu 